\title{
Study on Vibration and Stability Analysis of Thick Rectangular Plates Section
}

\author{
Ebirim, Stanley I. ${ }^{1}$, Ozuluonye C.G. ${ }^{2}$, Anya U.C ${ }^{3}$, Ibearugbulem Owus M $^{4}$ \\ ${ }^{1,}$ Department of Civil Engineering, Gregory University Uturu, Abia State, Nigeria \\ ${ }^{2-4}$ Department of Civil Engineering, Federal University of Technology, Owerri, Nigeria
}

\begin{abstract}
This paper is the second part of free vibration and stability analysis of thick isotropic and orthotropic plates. The support condition CCCC and CCFC support was considered by applying the alternative II theory based on polynomial shape function. The work was based on the application of the formulation earlier derived using Ritz method. The frequency values of the first mode and critical loads obtained were compared with those obtained using first order shear deformation theory. For span to depth ratio of 10, the fundamental linear frequency for orthotropic CCFC plate corresponding to modulus of elasticity ratios $\left(E_{1} / E_{2}\right)$ of 10,25 and 40 were $0.00312 \mathrm{~Hz}, 0.00373 \mathrm{~Hz}$ and $0.00398 \mathrm{~Hz}$.

Keywords: Fundamental natural frequency, CCCC plate, CCFC plate, Ritz method, Orthotropic thick plate, Isotropic thick plate, Stability, Free vibration.
\end{abstract}

Keywords: $C C C C$ and $C C F C$ Support conditions, Natural frequency, Shear deformation, Vibration, Stability Analysis.

\section{INTRODUCTION}

Rectangular thin or thick plates are the most important structural component in this present age, due to the advancement in technology which provides easy installation. The thin plate theory also known as classical plate theory (CPT) was well explained [1]. Additionally, the evolution of theories such as first shear deformation (FSDT) and higher order shear deformation used in the analysis of plate can be seen in [2] and [4], where three -dimensional elasticity theory (TDET)was mentioned. [3] applied the double finite integral transform method to the buckling problems of rectangular Mindlin plates, with focus on typical non-Lévytype fully clamped plates. Via the integral transform, the PDEs governing the bucking of a thick plate was reduced to a system of linear algebraic equations. The analytic buckling load solutions were then readily determined by the existence of nonzero solutions of the system of equations.

A limited body of literature exists for the free vibration of such thick plates, but most of it is based on theory of thin plate. Such literature may be found in Liew et al. [16] excellent reviews. This extensive study of rectangular thick CCCC and CCFC plates was encouraged by the non-availability of design data. It is obviously a very complex job to include all research findings in a single paper. Hence, the Need to separate the findings into a three papers. The first part dealt with the comprehensive formulation for free vibration and stability of rectangular thin, thick, isotropic and orthotropic plates. The formulation was validated when applied to CCCC and CCFC plates [1]. The second part (present study) shows the application of the derived formula to CCCC and CCFC plates.

\subsection{Application of fundamental natural frequency and stability formula to CCCC and CCFC plates}

The formulation of fundamental natural frequency and stability of plate, either thin or thick, isotropic or orthotropic has been derived [1] as:

$\omega=\frac{1}{a \beta} \sqrt{\frac{E_{0} \cdot\left(r_{11}+r_{12} T_{2}+r_{13} T_{3}\right)}{12\left\langle 1-\mu_{12} \mu_{21}\right\rangle \cdot \rho \cdot k_{\lambda}}}$

And for stability

$\frac{N_{R} a^{2}}{E_{0} t^{3}}=\frac{1}{12\left\langle 1-\mu_{12} \mu_{21}\right\rangle} \cdot\left(\frac{r_{11}+r_{12} T_{2}+r_{13} T_{3}}{k_{N R}}\right)$

Where: 
$\beta=\frac{a}{t} ; \mu_{12} \mu_{21}=$ poission ratio $\rho=$ density of plate material

$k_{\lambda}=\int_{00}^{11} \int^{2} h^{2} d R d Q$

$T_{2}=\frac{\left(r_{23} r_{31}-r_{21} r_{33}\right)}{\left(r_{22} r_{33}-r_{23} r_{23}\right)}$

$T_{3}=\frac{\left(r_{23} r_{21}-r_{22} r_{31}\right)}{\left(r_{22} r_{33}-r_{23} r_{23}\right)}$

Equation (1) is for natural frequency while Equation (2) is for stability analyses of isotropic and orthotropic rectangular thin and thick plate.

\section{NUMERICAL EXAMPLE}

It is desired to determine the critical buckling loads, fundamental natural and linear frequencies for CCCC and CCFC rectangular thick plates. The values of parameters used are given by Ghugal and Pawar [4]. For stability of orthotropic plate $E_{1} / E_{2}=$ 10,25 and $40, G_{12} / E_{2}=0.5, G_{13} / E_{2}=0.5, G_{23} / E_{2}=0.2, v_{12}=0.25, \rho=7800 \mathrm{~kg} / \mathrm{m}^{3}$. The diagrams of CCCC and CCFC rectangular plates loaded with in-plane load along $\mathrm{x}$ direction are shown on Figures 1 and 2.

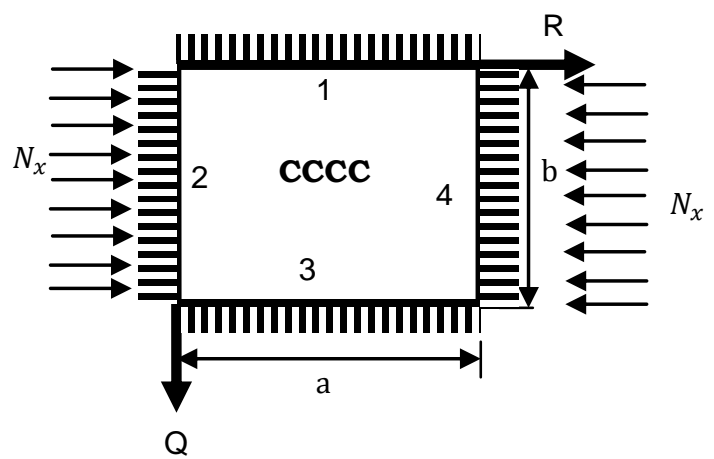

Figure 1: Numbering Style CCCC Plate

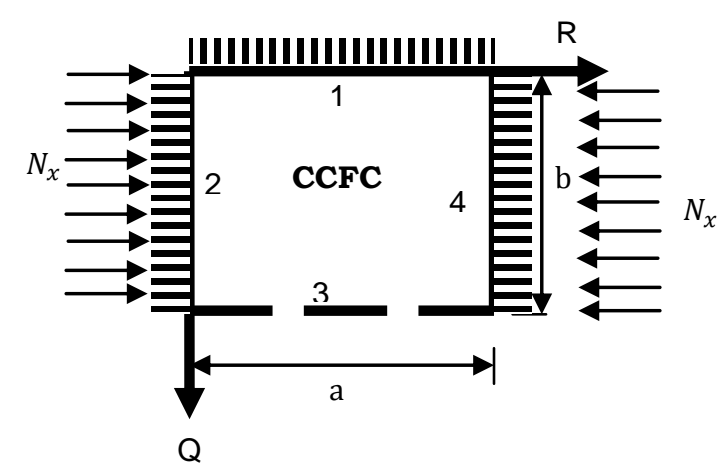

Figure 2: Numbering Style CCFC Plate

\subsection{Solution to the example}

The particular deflection function that satisfies the boundary conditions for CCCC plate[5] is:

$w=A\left(S_{1} R^{2}+T_{1} R^{3}+R^{4}\right)\left(S_{1} Q^{2}+T_{1} Q^{3}+Q^{4}\right) ; \quad$ Where $S_{1}=1$ and $T_{1}=-2$

The particular deflection function that satisfies the boundary conditions for CCFC plate [5]is:

$w=A\left(R^{2}-2 R^{3}+R^{4}\right)\left(S Q^{2}+T Q^{3}+Q^{4}\right)$

Where:

$S_{2}=\left(\frac{n_{13} n_{22}-n_{23} n_{12}}{n_{11} n_{22}-n_{21} n_{12}}\right)$ and $T_{2}=\left(\frac{n_{13} n_{21}-n_{23} n_{11}}{n_{21} n_{12}-n_{11} n_{22}}\right)$

$n_{11}=0.125 P^{2}-3 \mu_{21} ; \quad n_{12}=0.375 P^{2}-3 \mu_{21} ; \quad n_{13}=3 \mu_{21}-0.75 P^{2}$

$n_{21}=4-2 \mu_{21} ; \quad n_{22}=3 \mu_{21}-6+0.375 P^{2} ; \quad n_{23}=8-1.5 P^{2}-4 \mu$

The stiffness coefficients for CCCC and CCFC plates [5] are presented in Table 1.

Table 1: K value for CCCC and CCFC plates

\begin{tabular}{|l|c|c|}
\hline Parameters & CCCC & CCFC \\
\hline $\boldsymbol{K}_{\boldsymbol{R}}$ & 0.0012698 & {$\left[0.2 S^{2}+0.3333 S T+0.2857 S+0.1429 T^{2}+0.25 T+0.11\right] 0.8$} \\
\hline $\boldsymbol{K}_{\boldsymbol{R} Q}$ & 0.0003628 & {$\left[1.3333 S^{2}+3 S T+3.2 S+1.8 T^{2}+4 T+2.288\right] 0.01905$} \\
\hline $\boldsymbol{K}_{\boldsymbol{Q}}$ & 0.0012698 & {$\left[4 S^{2}+12 S T+16 S+9 T^{2}+36 T+28.80\right] 0.001587$} \\
\hline $\boldsymbol{K}_{N R}$ & 0.0000302 & {$\left[0.2 S^{2}+0.3333 S T+0.2857 S+0.1429 T^{2}+0.25 T+0.11\right] 0.001587$} \\
\hline $\boldsymbol{K}_{N Q}$ & 0.0000302 & {$\left[1.3333 S^{2}+3 S T+3.2 S+1.8 T^{2}+4 T+2.288\right] 0.001587$} \\
\hline $\boldsymbol{K}_{\lambda}$ & 0.0000025 & {$\left[0.2 S^{2}+0.3333 S T+0.2857 S+0.1429 T^{2}+0.25 T+0.11\right] 0.03333$} \\
\hline
\end{tabular}


International Journal of Advances in Scientific Research and Engineering (ijasre), Vol 7 (4), April -2021

Note that, $\quad E_{0}=E_{2}=1=e_{22}$. Thus, $\quad e_{11}=E_{1} ; \quad e_{12}=\mu_{21} E_{1} ; \quad e_{33}=\left(1-\mu_{12} \mu_{21}\right) G_{12}$

$e_{44}=\left(1-\mu_{12} \mu_{21}\right) G_{13} ; \quad e_{55}=\left(1-\mu_{12} \mu_{21}\right) G_{23} ; \quad D_{0}=\frac{E_{0} t^{3}}{12\left\langle 1-\mu_{12} \mu_{21}\right\rangle} ; \quad \frac{D_{0}}{t^{3}}=\frac{E_{2}}{12\left\langle 1-\mu_{12} \mu_{21}\right\rangle}$

The example problem was also solved using HPSDT, HSDT, TSDT, FSDT and CPT.

\section{RESULT AND DISCUSSION}

The results of the various analysis using the various plate theories are presented in Table 2 to Table 5. Table 2 shows the nondimensional natural frequency for CCCC plate obtained from the present study (using Equation (1)) and value obtained using three -dimensional elasticity theory. Table 3 shows the non-dimensional buckling load factors for CCCC isotropic plates under uniaxial compression. The non-dimensional buckling load factors for simply supported orthotropic plates under uniaxial compression for $v=0.25$ are shown in Table 4 while Table 5 shows the fundamental (linear) frequencies of vibration for CCCC and CCFC orthotropic plates

Table 2: Non-dimensional frequencies of vibration for $\mathrm{CCCC}$ plate with aspect $\mathrm{ratio}, \mathrm{a} / \mathrm{b}=1$ and span to depth $\mathrm{ratio}, t / a=$

\begin{tabular}{|c|c|c|}
\multicolumn{3}{|c|}{ 0.1. $\overline{\boldsymbol{\omega}}_{\boldsymbol{b}}=\boldsymbol{\omega} /(\boldsymbol{b} \boldsymbol{\pi})^{2} \sqrt{\boldsymbol{D} / \boldsymbol{\rho} \boldsymbol{}}$} \\
\hline \multicolumn{3}{|c|}{ Theory } \\
\hline TDET [3] & $\begin{array}{c}\text { Present study } \\
\text { (Alternative II) }\end{array}$ & \% Diff \\
\hline 3.3215 & 3.4335 & 3.26 \\
\hline
\end{tabular}

Table 3: Non-dimensional buckling load factors for CCCC plates under uniaxial compression, $\mathbf{a} / \mathbf{b}=1$

\begin{tabular}{|c|c|c|}
\hline $\mathbf{t} / \mathbf{a}$ & FEA [3] & $\begin{array}{l}\text { Present study (Alternative II) } \\
\qquad \overline{N_{R}}=\frac{N_{R} a^{2}}{\pi^{2} D}\end{array}$ \\
\hline 0.05 & 9.5595 & 10.6019 \\
\hline 0.1 & 8.2921 & 9.69605 \\
\hline 0.15 & 6.7597 & 8.48740 \\
\hline 0.2 & 5.3157 & 7.22630 \\
\hline
\end{tabular}

Table 4: Non-dimensional buckling load factors for CCCC orthotropic plates under uniaxial compression $\mathrm{v}=0.25$

\begin{tabular}{|c|c|c|c|c|}
\hline \multirow{3}{*}{$\mathbf{a} / \mathbf{t}$} & \multirow{3}{*}{ Theory } & \multicolumn{3}{|c|}{$\overline{N_{R}}=\frac{N_{R} a^{2}}{E_{2} t^{3}}$} \\
\hline & & \multicolumn{3}{|c|}{$\mathbf{E}_{1} / \mathbf{E}_{2}$} \\
\hline & & 10 & 25 & 40 \\
\hline 10 & Alternative II & 24.9015 & 35.6988 & 40.5530 \\
\hline 20 & Alternative II & 35.3441 & 66.0213 & 87.2509 \\
\hline 100 & Alternative II & 40.9698 & 92.1624 & 142.3210 \\
\hline
\end{tabular}


International Journal of Advances in Scientific Research and Engineering (ijasre), Vol 7 (4), April -2021

Table 5: Comparison of fundamental (linear) frequencies of vibration for CCCC and CCFC orthotropic plates

\begin{tabular}{|c|c|c|c|c|c|c|c|}
\hline \multirow{3}{*}{$\mathbf{a} / \mathbf{t}$} & Source & \multicolumn{3}{|c|}{ CCCC } & \multicolumn{3}{c|}{ CCFC } \\
\cline { 3 - 8 } & $\mathbf{E}_{\mathbf{1}} / \mathbf{E}_{\mathbf{2}}=\mathbf{1 0}$ & $\mathbf{E}_{\mathbf{1}} / \mathbf{E}_{\mathbf{2}}=\mathbf{2 5}$ & $\mathbf{E}_{\mathbf{1}} / \mathbf{E}_{\mathbf{2}}=\mathbf{4 0}$ & $\mathbf{E}_{\mathbf{1}} / \mathbf{E}_{\mathbf{2}}=\mathbf{1 0}$ & $\mathbf{E}_{\mathbf{1}} / \mathbf{E}_{\mathbf{2}}=\mathbf{2 5}$ & $\mathbf{E}_{\mathbf{1}} / \mathbf{E}_{\mathbf{2}}=\mathbf{4 0}$ \\
\hline \multirow{4}{*}{10} & Present $(\omega)$ & 0.0196 & 0.0234 & 0.0250 & 0.0183 & 0.0224 & 0.0241 \\
\cline { 2 - 8 } & Present $(\lambda)$ & 0.00312 & 0.00373 & 0.00398 & 0.00292 & 0.00357 & 0.00383 \\
\cline { 2 - 8 } & {$[6](\lambda)$} & 0.00286 & 0.00330 & 0.00346 & 0.00264 & 0.00312 & 0.00330 \\
\hline \multirow{4}{*}{20} & Present $(\omega)$ & 0.0117 & 0.0159 & 0.0183 & 0.0110 & 0.0155 & 0.0179 \\
\cline { 2 - 8 } & Present $(\lambda)$ & 0.00186 & 0.00254 & 0.00292 & 0.00175 & 0.00246 & 0.00285 \\
\cline { 2 - 8 } & {$[6](\lambda)$} & 0.00180 & 0.00238 & 0.00269 & 0.00167 & 0.00230 & 0.00262 \\
\hline \multirow{4}{*}{100} & Present $(\omega)$ & 0.0025 & 0.0038 & 0.0047 & 0.0024 & 0.0037 & 0.0046 \\
\cline { 2 - 8 } & Present $(\lambda)$ & 0.00040 & 0.00060 & 0.00074 & 0.00038 & 0.00059 & 0.00073 \\
\cline { 2 - 8 } & {$[6](\lambda)$} & 0.00040 & 0.00060 & 0.00074 & 0.00037 & 0.00058 & 0.00073 \\
\hline
\end{tabular}

\section{DISCUSSION OF RESULTS}

Table 2 shows the comparison of non-dimensional fundamental frequencies of vibration for simply supported isotropic plate with aspect ratio $\mathrm{a} / \mathrm{b}=1$ and $\mathrm{t} / \mathrm{a}=0.1$. The percentage difference with [2] value is $3.26 \%$. The difference in the results can be attributed to the non-inclusion of shear deformation parameters and following CPT method by previous researchers. Table 3 shows the comparison between the present study and FEA [3] for non-dimensional buckling load factors for CCCC isotropic plates under uniaxial compression. The value of non-dimensional buckling load factors for CCCC orthotropic plates under uniaxial compression is shown on Table 4. The result, which is obtained using, $\overline{N_{R}}=\frac{N_{R} a^{2}}{E_{2} t^{3}}$ shows values for various span/thickness (a/t) ratio and $E_{1} / E_{2}$. As at the time of this study, there is no literature to compare the results. Finally, Table 5 shows the results of fundamental linear frequencies of vibration of orthotropic plates (CCCC and CCFC). The validity of numeric values from Abaqus[6] which is based on Mindlin - Reissner theory with approximate global size of 0.05 . At span to depth ratio of 100 (thin plate), both CCCC and CCFC plates have the same result for [6] and present study. However, the results differ for span to depth ratio of 10 and 20 due to non-inclusion of shear deformation parameters as explained earlier.

In conclusion, the study has shown significant difference in percentage with respect to thick rectangular plates. This might lead to instability or noticeable vibration of structure, for example early cracks, settlement and buckling of structural elements. This method is simply, non-rigorous and straight forward when compared with the methods used in previous researches

\section{REFERENCES}

[1] O. M. Ibearugbulem, S. I. Ebirim, U. C. Anya, and L. O. Ettu, ‘Application Of Alternative Ii Theory To Vibration And Stability Analysis Of Thick Rectangular Plates ( Isotropic And Orthotropic )’, vol. 39, no. 1, pp. 52-62, 2020.

[2] K. M. Liew, K. C. Hung, and M. K. Lim, 'A Continuum three-dimensional vibration analysis of thick rectangular plates', International Journal of Solids and Structures, vol. 30, no. 24, pp. 3357-3379, 1993.

[3] S. Ullah, H. Wang, and X. Zheng, 'New analytic buckling solutions of moderately thick clamped rectangular plates by a straightforward finite integral', Archive of Applied Mechanics, pp. 1-13, 2019, DOI: 10.1007/s00419-019-01549-6.

[4] Ghugal and M. Pawar, 'Buckling and vibration of plates by hyperbolic shear deformation theory, Journal of Aerospace Engineering \& Technology, vol. 1, no. 1, pp. 1-12, 2011.

[5] S. Ebirim, 'o', Unpublished Ph.D. Thesis, Department of Civil Engineering, Federal University of Technology, Owerri, Imo State, Nigeria, 2018.

[6] Simulia, 'Abaqus/CAE Student version'. 2017.

c. E-mail addresses: ${ }^{1}$ stanley.ebirim@gmail.com ${ }^{2}$ anyauchukwu@gmail.com , ${ }^{4}$ ibeowus@gmail.com 